\title{
Frequency and Microenvironmental Pattern of Selection on Plastic Shade-Avoidance Traits in a Natural Population of Impatiens capensis
}

\author{
Heidrun Huber, ${ }^{\star}$ Nolan C. Kane, ${ }^{\dagger}$ M. Shane Heschel, ${ }^{\ddagger}$ Eric J. von Wettberg, ${ }^{\S}$ Joshua Banta," \\ Anne-Marie Leuck, and Johanna Schmitt
}

Department of Ecology and Evolutionary Biology, Brown University, Providence, Rhode Island 02912

Submitted April 7, 2003; Accepted September 24, 2003;

Electronically published April 19, 2004

Online enhancements: appendix tables.

AвstRACт: The frequency and predictability of different selective environments are important parameters in models for the evolution of plasticity but have rarely been measured empirically in natural populations. We used an experimental phytometer approach to examine the frequency, predictability, and environmental determinants of heterogeneous selection on phytochrome-mediated shade-avoidance responses in a natural population of the annual plant Impatiens capensis. The strength and direction of selection on shade-avoidance traits varied substantially on a fine spatial scale. The shade-avoidance phenotype had high relative fecundity in some microsites but was disadvantageous in other microsites. Local seedling density proved to be a surprisingly poor predictor of microenvironmental variation in the strength and direction of selection on stem elongation in this study population. At least some of this unpredictability resulted from microenvironmental variation in water availability; the shade-avoidance phenotype was more costly in dry microsites. Thus, environmental heterogeneity in resource availability can affect the relative costs and benefits of expressing shade-avoidance traits independent

* Corresponding author. Present address: Experimental Plant Ecology, Department of Ecology, University of Nijmegen, Toernooiveld 1, 6525 ED Nijmegen, The Netherlands; e-mail: heidrun.huber@sci.kun.nl.

† Present address: Department of Biology, Indiana University, Bloomington, Indiana 47405; e-mail: nkane@indiana.edu.

₹ Present address: Harvard University Herbaria, Cambridge, Massachusetts 02138; e-mail: sheschel@oeb.harvard.edu.

` E-mail: eric_von_wettberg@brown.edu.

" Present address: Department of Ecology and Evolutionary Biology, University of Tennessee, Knoxville, Tennessee 37996; e-mail: jbanta@utk.edu.

" E-mail: johanna_schmitt@brown.edu.

Am. Nat. 2004. Vol. 163, pp. 548-563. () 2004 by The University of Chicago. 0003-0147/2004/16304-30133\$15.00. All rights reserved. of local seedling density, the inductive environmental cue. Theory predicts that these conditions may promote local genetic differentiation in reaction norms in structured populations, as observed in I. capensis.

Keywords: environmental heterogeneity, Impatiens capensis, natural selection, shade-induced plasticity, path analysis, phenotypic manipulation.

The evolution of phenotypic plasticity, the ability of a genotype to express different phenotypes in response to environmental variation, is a subject of intense theoretical interest (e.g., Bradshaw 1965; Via and Lande 1985; Schlichting 1989; van Tienderen 1991; Gomulkiewicz and Kirkpatrick 1992; Scheiner 1993, 1998; de Jong 1995, 1999; Tufto 2000; Sultan and Spencer 2002). For plasticity to evolve, organisms must experience heterogeneous environments, selection on a plastic trait must differ among those environments, and genetic variation must exist within populations for reaction norms of that trait (Via and Lande 1985; Gomulkiewicz and Kirkpatrick 1992). Theory predicts that the evolution of plasticity in heterogeneous environments will depend on the frequency of environments selecting for different phenotypes, the relative strength of selection in each environment, the reliability of the inductive environmental cue, the cost of maintaining the capacity for plasticity, and the genetic variances and covariances within and across environments (e.g., Via and Lande 1985; van Tienderen 1991; Gomulkiewicz and Kirkpatrick 1992; Kawecki and Stearns 1993; de Jong 1999; Tufto 2000). Recent empirical studies have quantified most of these parameters. There is now substantial evidence for environment-dependent selection on plastic traits (e.g., Kingsolver 1995a, 1995b, 1996; Dudley and Schmitt 1996; Dorn et al. 2000) and little evidence that maintenance costs will constrain the evolution of adaptive plasticity (DeWitt 1998; DeWitt et al. 1998; Scheiner and Berrigan 1998; Donohue et al. 2000a; Dorn et al. 2000). Quantitative genetic variation in reaction norms 
and the genetic architecture of plasticity have also been studied in a variety of systems (e.g., Pigliucci et al. 1995; Sultan 1995; Fry et. al 1996; Donohue and Schmitt 1999; Donohue et al. 2000b, 2001; Kliebenstein et al. 2002; Olsson and Uller 2002). However, few studies have attempted to quantify other important parameters: the frequency and predictability of different selective environments acting on plastic traits within natural populations (Weis and Gorman 1990; Kingsolver et al. 2001; Arnold and Peterson 2002). The frequency and pattern of selection on plastic traits is especially important for sessile organisms like plants, which experience environmental heterogeneity in natural selection on a fine spatial scale (Kalisz 1986; Stewart and Schoen 1987; Stratton 1995; Stratton and Bennington 1996). Here we examine the microenvironmental pattern, frequency, and predictability of natural selection on phytochrome-mediated shade-avoidance responses in a natural plant population.

Environmental variation selects on plasticity by altering the relative benefits and costs of expressing an induced phenotype. Induction of trait expression by an environmental cue associated with a selective agent is often assumed to enhance fitness. However, expression of a plastic trait may be associated with performance reductions due to correlated effects of plastic responses on other traits (DeWitt 1998; DeWitt et al. 1998). For example, induction of spines in response to cues of predator proximity will only be advantageous if the fitness benefit of reduced predation risk exceeds potential fitness costs of spine production, such as reduced growth rate. The costs of expressing an induced phenotype may outweigh the benefits if that phenotype exacts a high physiological cost in lowresource environments. If so, plasticity will not confer a selective advantage under low-resource conditions. In this case, environmental heterogeneity in resource availability may reduce the reliability of the inductive environmental cue for predicting the relative fitness of the induced phenotype. It is therefore important to ask whether the fitness of an induced phenotype depends on environmental variation, not only in selection by the inductive agent but also in the availability of resources that could affect the cost of expression. Moreover, it is important to assess the reliability of the inductive cue for predicting the selective environment experienced by an organism under natural conditions.

The photomorphogenic induction of shade-avoidance responses in crowded plants is a well-studied example of adaptive plasticity (e.g., Morgan and Smith 1979; Ballaré et al. 1987, 1990; Casal and Smith 1989; Schmitt and Wulff 1993; Dudley and Schmitt 1996; Schmitt et al. 2003). Shade avoidance involves a whole suite of developmental responses, notably stem elongation and reduced branching (Smith 1982; Schmitt and Wulff 1993). These morpho- logical changes are mediated by the phytochrome family of photoreceptors, which detect the low ratio of red : far red radiation ( $\mathrm{R}: \mathrm{FR})$ reflected or transmitted from neighboring plants in dense stands (Ballaré et al. 1987, 1990; Smith 1995). Early detection of neighbors may allow plants to develop the morphology appropriate for the competitive environment they will experience (Ballaré et al. 1987, 1990; Novoplansky et al. 1990; Aphalo and Ballaré 1995). The ratio of red : far red radiation is an accurate cue of neighbor proximity (Smith et al. 1990), and stem elongation in response to variation in $\mathrm{R}$ : FR and density is a continuous, graded response (Smith 1982; Smith and Whitelam 1997; Ballaré et al. 1990; Gilbert et al. 2001; Schmitt et al. 2003). The main benefit of phytochrome-mediated stem elongation in response to crowding is that leaves can be positioned in higher regions of the canopy, thereby enhancing light interception and increasing fitness under high densities (Schmitt et al. 1995; Dudley and Schmitt 1996; Huber and Wiggermann 1997; Huber et al. 1998; Weinig 2000). However, expression of the shade-avoidance phenotype may be costly at low density (Schmitt and Wulff 1993; Casal et al. 1994). For example, exposure to low R: FR results in decreased allocation to roots, which may constrain water uptake capacity and make plants more susceptible to drought (Maliakal et al. 1999). The shadeavoidance response also produces thinner, mechanically weaker stems, which may have a higher risk of lodging or breaking (Schmitt and Wulff 1993; Casal et al. 1994; Niklas 1995; Cipollini and Schultz 1999). Plastic shade avoidance is known to be adaptive in the annual species Impatiens capensis under natural conditions; plants expressing the shade-avoidance phenotype have higher fitness in dense stands, but lower fitness at low density, than plants in which shade-avoidance responses are not induced (Dudley and Schmitt 1996). The fitness disadvantage of shade avoidance at low density cannot be attributed to direct selection on height, and the underlying mechanism for this cost remains to be determined (Dudley and Schmitt 1996).

These results suggest that the benefit of expressing shade-avoidance traits will vary with plant density, which induces those traits via the R: FR cue, in natural populations. However, the costs and benefits of shade avoidance may also vary with other environmental factors, which may not be highly correlated with density. Specifically, drought stress may increase the cost of reduced allocation to root tissue in plants expressing shade-avoidance phenotypes (Maliakal et al. 1999). As a consequence, elongated plants should have a relatively higher fitness in moist microsites, whereas nonelongated plants should have relatively higher fitness in dry microsites. We can also predict that high degrees of tree canopy openness may increase the fitness benefit to shade-avoidance phenotypes because 
the carbon acquisition gain from overtopping neighbors may be higher under high light conditions than under deep canopy shade. If so, the advantage of plastic shade avoidance may be greater in high-resource environments. However, little is known about the frequency or predictability of environments selecting on shade-avoidance traits in natural plant populations, or how their frequency distribution depends on variation in resource availability.

Here we report on the frequency, predictability, and environmental determinants of selection on shade-avoidance traits in a natural population of the annual plant $I$. capensis. This system is especially appropriate because density-dependent selection on shade-avoidance traits has been demonstrated, as predicted if plasticity is adaptive (Dudley and Schmitt 1996), and because substantial genetic variation in shade-avoidance traits exists within and between natural populations (Dudley and Schmitt 1995; Donohue and Schmitt 1999; Donohue et al. 2000b, 2001). To measure environmental variation in selection on shadeinduced stem elongation, we experimentally extended the range of phenotypic expression (e.g., Dudley and Schmitt 1996; Cipollini and Schultz 1999; Schmitt et al. 1999) by manipulating the R: FR cue to produce two sets of seedlings in which the expression of shade-induced stem elongation was induced or not induced. We planted these seedlings into randomly chosen microsites in the natural source population and measured their relative fitness as well as environmental parameters for each microsite. This design allowed us to address the following questions: Are different phenotypes favored in different microsites within a natural population? What is the frequency distribution of selective environments for plastic shade-avoidance traits under natural conditions? Is the inductive cue, local seedling density, a reliable predictor of selection on shade-avoidance traits within a microsite? Does the relative fitness of plants with initially induced elongation depend on microenvironmental variation in water or light resource availability, as predicted by functional hypotheses?

\section{Material and Methods}

\section{Study Species}

Impatiens capensis Meerb. (Balsaminaceae) is an annual, self-compatible herb of North American deciduous forests and wetlands (Gleason and Cronquist 1963; Leck 1979, 1996). Impatiens capensis has a mixed mating system, commonly producing self-fertilizing cleistogamous flowers as well as outcrossing chasmogamous flowers (Waller 1979). Seeds usually disperse $<1.5 \mathrm{~m}$ from parent plants (Schmitt et al. 1985), and substantial microgeographic genetic differentiation exists in morphological and life-history traits (Argyres and Schmitt 1991; Schmitt 1993) and plastic shade-avoidance responses (Dudley and Schmitt 1995; Donohue and Schmitt 1999; Donohue et al. 2000a, 2000b, 2001) both within and among natural populations. In summer 1996, seedlings were collected from a $40 \times 40$ m permanent grid (Schmitt and Gamble 1990; Argyres and Schmitt 1991) in the center of a primarily selfing population in the understory of an oak-hickory forest at Brown University's Haffenreffer reserve (Bristol, Rhode Island), the site of a previous experiment demonstrating density-dependent selection on shade-avoidance traits (Dudley and Schmitt 1996). This population exhibits significant genetic variation in morphological and life-history traits and in plasticity to light availability, canopy shade, and crowding (Argyres and Schmitt 1991; Schmitt 1993; Donohue et al. 2000b, 2001). The seedlings were grown in the greenhouse to start a collection of inbred lines. These lines were maintained in the greenhouse by single-seed descent for six generations.

\section{$R: F R$ Pretreatments}

From December 1999 to January 2000, seventh generation selfed seeds were collected from four parent plants from each of eight lines. As inbreeding is the norm in the source population, we do not expect significant effects of inbreeding depression on the phenotypic expression of the lines used for this experiment. These seeds were stored in microtiter trays filled with distilled water at $4^{\circ} \mathrm{C}$. On April 11 , the seeds, most of which had emerging radicles, were planted into eight plug trays filled with Metromix 350 (Scotts Sierra Horticultural Products, Marysville, Ohio). The $28 \times 55-\mathrm{cm}$ plug trays had 128 cells (in eight rows and 16 columns), each yielding an average distance between seedlings of $3 \mathrm{~cm}$. This distance between seedlings elicits crowding-induced elongation. One seed per line was planted in a randomized position into each row. The total number of seeds planted was 880 (eight lines, two pretreatments, 55 replicates). The trays were placed in the Brown University greenhouse under natural light conditions.

After $10 \mathrm{~d}$, when almost all seedlings had emerged and produced their first true leaf pair, we imposed a R:FR manipulation. Four trays were allocated to each of two pretreatments to induce two different phenotypes. Half of the seedlings were grown under a plastic panel designed to remove far red light (Mitsui Chemical, Tokyo), thus artificially maintaining a high, $18: 1 \mathrm{R}: \mathrm{FR}$ ratio above the canopy and suppressing density-induced elongation in the plants (e.g., Ballaré et al. 1991; Dudley and Schmitt 1996). The panel reduced photosynthetically active radiation by $30 \%$. The remaining trays were placed under a clear plastic panel covered with cheesecloth to match the amount of radiation intercepted by the plants between the two pre- 
treatments. In this treatment, the normal reduction of $\mathrm{R}$ : FR at high seedling density induced elongation. Plants subjected to the high and low R: FR will henceforth be referred to as nonelongated and elongated, respectively. We surrounded trays in both pretreatments with sheets of aluminum foil in order to reflect lateral radiation and reduce edge effects. The trays were rotated within pretreatments every 3-4 d. On May 1, $1 \mathrm{~d}$ before planting, we measured seedling height, length of the longest leaf, and number of nodes. Initial height differences such as those seen among elongated and nonelongated experimental plants are potentially important for lifetime fecundity even if plants later respond plastically to their new environment after planting (Dudley and Schmitt 1996). In the first few weeks after emergence, the competitive hierarchy is formed, and slight early growth advantages can translate into considerable fitness differences later in the season (e.g., Schmitt et al. 1987; Schmitt and Ehrhardt 1990).

\section{Field Experiment}

On May 2 and May 3, 2000, we planted seedlings into 50 microsites at randomly chosen positions within a $40 \times 40-\mathrm{m}$ permanent grid in the center of the source population at the Haffenreffer Reserve (fig. 1). The dimension of each microsite was $60 \times 60 \mathrm{~cm}$. Into each microsite, one elongated seedling and one nonelongated seedling of each of the eight lines were planted in a $4 \times 4$ checkerboard design at 20 - $\mathrm{cm}$ spacing to minimize interaction between the experimental plants. The plants were ringed at the base with colored plastic-coated wire to facilitate identification. During planting, care was taken to keep the natural vegetation intact. Transplanted seedlings were approximately the same size and developmental stage as natural I. capensis seedlings in the site. Plants dying within the first $3 \mathrm{~d}$ after planting were replaced with seedlings from the same line and pretreatment whenever possible. Due to variable germination rate among lines, elongated and nonelongated pairs of each line could not be replicated in all 50 microsites. Per line pretreatment pairs could be replicated in 40-50 microsites for a total of 770 experimental plants. Assignment of lines to microsites was random, and each microsite contained pretreatment pairs from at least six lines. Throughout the experiment, we counted number of flowers, immature fruits, mature fruits, and pedicels every $10 \mathrm{~d}$. Lifetime relative fecundity for each individual was calculated as the total number of fruits produced during the course of the experiment divided by the overall mean number of fruits. Overall mortality before the onset of reproduction was very low for both experimental and naturally occurring I. capensis plants. Only three experimental plants died between 1 wk after trans-

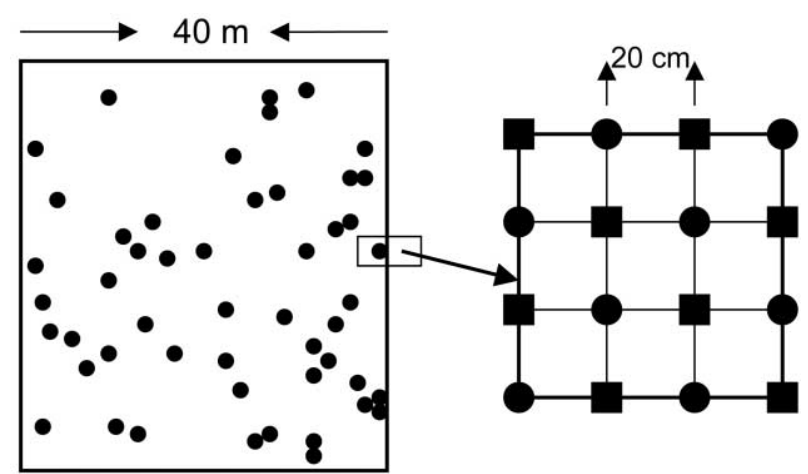

Figure 1: Setup of the experiment. Left, map of the field site with locations of the 50 randomly positioned microsites. Right, arrangement of elongated (solid square) and nonelongated (solid circle) plants within each microsite.

planting and the onset of fruit production. Their fecundity was scored as 0 . Mortality was scored twice a week until August 10 and thereafter once a week until the last plant had died. Individual longevity was calculated as the number of days from planting until the last date a plant was observed alive.

\section{Environmental Measurements}

On April 26, the number of naturally occurring seedlings of $I$. capensis was counted in each of the 50 microsites to estimate local density. Except for spring geophytes, I. capensis is the first species to emerge in the field. Initial seedling density was thus a good estimate for the initial competitive interaction experienced after the target seedlings were planted into the microsites, although interactions with other species may have become more important later in the growing season, after I. capensis had started to reproduce. Water availability for each microsite was measured as water vapor pressure deficit on July 24 using a soil tensiometer (2900 FI, Soil Moisture Equipment, Santa Barbara, Calif.). Water availability readings were performed in the six uppermost centimeters of the soil because I. capensis has a shallow root system (Heschel and Hausmann 2001). These data represent water availability on a typical day after a short period without rainfall (35 d; M. S. Heschel, unpublished data). Tensiometer readings on this date were highly correlated with measurements throughout the season (H. Huber, unpublished data), indicating that the ranking of microsites with respect to soil moisture was consistent through time. Light availability above the herbaceous understory was quantified by means of canopy images. A hemispheric image was taken above the center of each microsite after all experimental I. $c a$ pensis plants had died in the middle of September. Taking 
the picture in September allowed us to measure microsite light availability after canopy closure without disturbing the experimental plots during the experiment. The picture was taken with a Nikon Coolpix 950 Digital camera to which a Nikon FC-E Fisheye Converter was attached. Images were taken in late afternoon to avoid interference by direct sunlight. Light availability in the understory was quantified as the percentage of total light transmitted through the primary canopy (calculated as the sum of direct and indirect light) using Winphoto, version 5.0 (ter Steege 1996). The contribution of direct sunlight to total transmission changes throughout the season depending on the sun angle. Therefore, we calculated light transmission for June 13, which was at the peak of the growing period for I. capensis.

\section{Data Analysis}

We performed ANCOVA to test for effects of line, pretreatment, and line by pretreatment interaction on plant height before planting. Line and pretreatment were treated as fixed effects, and germination time (the number of days elapsed after planting) was used as a covariate to control for initial variation in size and developmental stage. We considered line a fixed effect in this analysis because it was necessary to choose high-fecundity lines for adequate replication and because our objective was to partition out variance due to differences among lines when testing for pretreatment and microenvironment effects, not to estimate the genetic variation of the source population. We also used ANCOVA to test for the effects of initial phenotype, line, and microenvironmental factors on individual longevity and lifetime fecundity. This model included pretreatment and line as fixed main effects; germination time, initial seedling density, water availability, and light availability as covariates; and the interactions of phenotype and line with the three environmental parameters.

Rather than analyzing traits on plant individuals, the focus of the experiment was to analyze the strength of selection on traits. In order to do so, we calculated the ratio of performance parameters between initially elongation-induced (e) and nonelongated (n) plants for each microsite. To adjust for the effect of differences in germination time, we took the residuals of lifetime fecundity and longevity on germination time and added the population mean to each residual to calculate adjusted values. Thereafter, we estimated the mean lifetime fecundity of elongation-induced plants relative to nonelongated plants by taking the mean of $\log \left(w_{\mathrm{e}} / w_{\mathrm{n}}\right)$ over the eight $\mathrm{R}: \mathrm{FR}$ pretreatment pairs (one for each line), where $w_{\mathrm{e}}$ is the adjusted lifetime fruit production of the initially elongated plant and $w_{\mathrm{n}}$ is the adjusted lifetime fruit production of the nonelongated plant for each line. We used the same procedure to estimate the mean relative longevity of initially elongated plants within each microsite. The ratio $w_{\mathrm{e}} /$ $w_{\mathrm{n}}$ was $\log$ transformed in order to reach a symmetrical distribution of the resulting ratios around 0 . This facilitated the comparison of the ratios, since a value $>0$ for a given microsite indicates selection favoring initial elongation plants in that microsite, whereas a value $<0$ indicates selection favoring the initially nonelongated phenotype.

We used SAS Proc Univariate to analyze distributions of microsite means for longevity ratio, fecundity ratio, and the three environmental parameters. To test whether the distributions of fecundity ratio and longevity ratio differed from random expectation, we used an SAS macro to generate an expected random distribution of microsite mean values. We did this by drawing longevity ratio and fecundity ratio for each of the eight genotypes at random from the observed values in the 50 experimental microsites, taking the mean of the eight randomly drawn values and repeating the procedure 10,000 times. Parameter values for microsites at which some genotypes were missing in the actual data set were included in the random assignment as missing values. To assess whether the distribution of the two performance parameters differed significantly from a random distribution, we tested whether the deviation of the observed mean, variance, skewness, and kurtosis of the measured plots differed statistically significantly from the mean, variance, skewness, and kurtosis obtained by the random distribution. If selection varied across microsites due to microenvironmental variation, we would expect the observed variance in fecundity ratio and longevity ratio to exceed the random expectation. The $t$ values were obtained by subtracting the distribution parameters characterizing the measured plots from the distribution parameters after randomization and dividing by the standard error of the randomized plots (Sokal and Rohlf 1995, box 7.1., 7.5.). Pearson correlation coefficients were calculated among the two performance measures and the three environmental parameters.

To test for direct and indirect effects of the environmental parameters on the relative fitness of elongated plants, we performed a path analysis using the program package AMOS (Arbuckle and Wothke 1999). In the path analysis, we calculated for the 50 microsites the direct effects of the two abiotic environmental factors (water, light) on the biotic environmental factor (seedling density) and tested for direct and indirect effects of these three factors on longevity ratio and fecundity ratio (fig. 6). We also included a direct path from longevity ratio to fecundity ratio to assess whether environmental factors influence the fecundity ratio through their effects on longevity ratio. Seedling density was square root transformed to improve normality for this analysis. 


\section{Results}

Effects of Pretreatment, Genotype, and Environmental Factors

At the onset of the experiment, plants with induced elongation were significantly taller than nonelongated plants (fig. 2; $F=2,828$, df $=1, P<.001$ ). Germination time had a significant effect on initial length $(P<.001)$. Adjusted for germination date, the mean height of the elongated plants was $10.79 \mathrm{~cm}(\mathrm{SE}=0.09)$, and that of the nonelongated plants was $4.67 \mathrm{~cm}(\mathrm{SE}=0.09)$. Lines differed significantly in their initial height $(F=17.1$, df $=$ $7, P<.001)$ as well as in their response to the pretreatments ( $F=7.71, \mathrm{df}=7, P<.001$; fig. 2$)$, with the initial plastic response to pretreatments ranging from $100 \%$ to $150 \%$ increased shoot length in the elongation induced as compared to the uninduced plants.

Across the study site, elongated plants produced slightly more fruits overall than nonelongated plants $(P=.036$; see appendix in the online edition of the American Naturalist for ANCOVA table). Adjusted for germination date, the mean number of fruits produced by the elongated plants was 13.06 ( $\mathrm{SE}=0.41)$, and that of the nonelongated plants was $12.36(\mathrm{SE}=0.40)$ However, the initial phenotype manipulation had no effect on overall longevity $(P=.724)$. Germination time also significantly affected lifetime fecundity $(P=.006)$ but not longevity $(P=$ $.151)$. Microsite water availability significantly affected both fruit production $(P<.001)$ and longevity $(P<.001)$; plants in wetter microsites survived longer and produced more seeds (unstandardized partial regression coefficients for longevity $=0.998, P<.001 ;$ fitness $=0.592$, $P<.001)$. As predicted, we observed a significant pretreatment $\times$ water interaction for both longevity $(P=.042)$ and fecundity $(P=.017)$; elongated plants were more sensitive to microenvironmental water availability (see path analysis results below). Microsite light availability did not affect plant performance $(P>.5)$. Microsite seedling density had no effect on fecundity $(P=$ $.484)$ but a strong effect on longevity $(P<.001)$. Plants surrounded by more conspecifics actually survived longer (unstandardized partial regression coefficient for longevity $=0.184, P=.037$ ), suggesting positive density dependence, in striking contrast with the negative density dependence and self-thinning observed in denser Impatiens capensis populations (Schmitt et al. 1987). Significant two-way interactions indicated that lines differed in response to pretreatment (longevity: $P=.051$; fecundity: $P=.013)$ and to water availability $(P<.01)$. In addition, the response of lines to water availability was significantly modified by pretreatments (longevity: $P=.023$; fecundity: $P=.010)$. None of the other interaction terms were significant either for longevity or for fecundity. Lines also

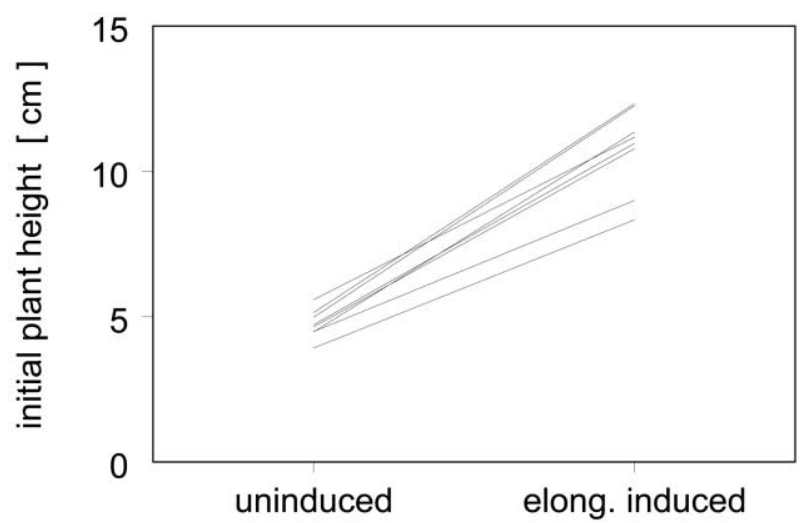

Figure 2: Initial shoot length of nonelongated and elongation-induced plants of the eight lines before planting into the field. ANCOVA revealed a significant effect of pretreatment $(F=2,828, P<.001)$, line $(F=$ $17.1, P<.001)$, a significant pretreatment $\times$ line interaction $(F=7.71$, $P<.001)$, as well as a significant effect of germination time ( $F=$ $159.9, P<.001)$ on shoot length.

differed significantly overall in longevity $(P=.005)$ but not in fecundity $(P=.636)$. There was a significant interaction between initial phenotype and line for both performance parameters.

\section{Frequency of Selection}

The strength and direction of selection on alternative phenotypes varied dramatically across microsites. The distribution of relative fecundity of elongated plants across 50 microsites was roughly bell shaped (fig. 3), ranging from 0.325 on a $\log$ scale (i.e., $110 \%$ greater fruit production by elongation induced plants) to -0.368 (i.e., $135 \%$ greater fruit production by nonelongated plants), with a mean of 0.037 . Thus, selection did not act strongly on variation in shade-avoidance traits in the most common microenvironments, and in the "average" environment the two phenotypes had roughly equal relative fitness; however, strong selection favoring each alternative phenotype occurred in different microsites within the population. The observed distribution of fecundity ratio across microsites displayed significantly higher variance and kurtosis, and was more skewed to the left, than the predicted random distribution (table 1). Thus, selection on shade-avoidance traits was more heterogeneous across microsites than expected by chance alone, suggesting the influence of some form of microenvironmental variation.

The frequency distribution of longevity ratio across microsites was also bell shaped (fig. 3), but the range, from -0.09 to 0.08 on a log scale, was much narrower than for fecundity ratio. In fact, in contrast with fecundity ratio, the observed variance, skewness, and kurtosis for longevity 

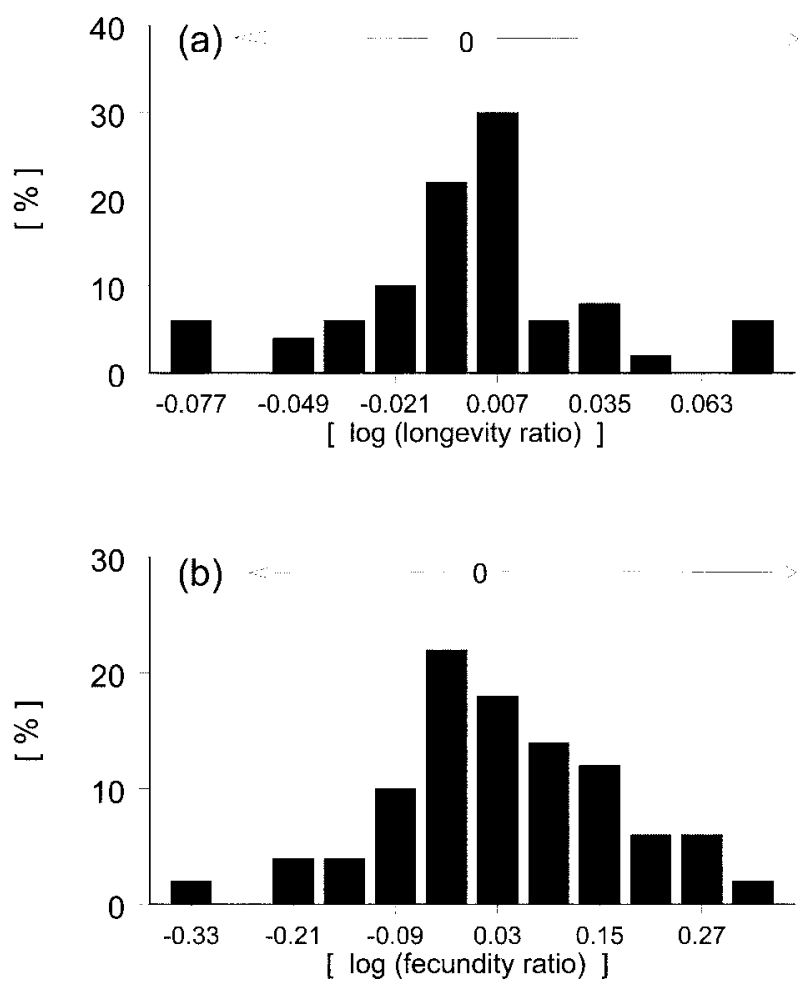

Figure 3: Frequency distribution (in percentage) of (a) mean longevity ratio and $(b)$ mean fecundity ratio of elongation-induced plants among the 50 plots (see text for description of calculations). Because fecundity ratio and longevity ratio are expressed at a $\log$ scale, a value $>0$ indicates selection favoring elongation-induced plants (depicted by right arrow), whereas a value $<0$ indicates selection favoring the uninduced phenotype (depicted by left arrow).

ratio were all significantly lower than the predicted random distribution (table 1), suggesting that some external factor acted to homogenize the relative longevity of elongated and nonelongated phenotypes across microsites. We attribute this result to a sudden episode of severe phenotypeindependent mortality between July 11 and July 18. On July 18, all plants had died in approximately $50 \%$ of the microsites. In $<25 \%$ of the microsites were more than half of the target plants still alive. Most plants of both phenotypes died in most microsites during this episode, resulting in more uniform longevity ratios across microsites than would be expected by chance alone.

\section{Environmental Variation}

Environmental parameters varied substantially among the 50 microsites. The density of naturally occurring seedlings of $I$. capensis early in spring (fig. $4 C$ ) varied substantially among microsites, ranging from 0 in one microsite to a maximum of 176 seedlings $\mathrm{m}^{-2}$. The mean seedling density in 2000 was 41.6 seedlings $\mathrm{m}^{-2}, 50 \%-80 \%$ lower than in typical years (M. S. Heschel, unpublished data); seedling density was $<40$ seedlings $\mathrm{m}^{-2}$ in $56 \%$ of the plots and exceeded 80 seedlings $\mathrm{m}^{-2}$ in only $12 \%$ of the microsites. These low densities probably resulted from low seed production in the previous year (1999), which was unusually dry (M. S. Heschel, unpublished data).

Water availability on July 24 (fig. $4 B$ ) ranged between -0.011 and $-0.038 \mathrm{MPa}$, with a mean around -0.026 and a mode around $-0.025 \mathrm{MPa}$. Forty-two percent of the microsites were wetter and $66 \%$ of the microsites were dryer than the mean. A soil moisture availability of about $-0.030 \mathrm{MPa}$ constitutes drought stress for I. capensis (Heschel and Hausmann 2001). This means that I. capensis plants in $40 \%$ of the microsites were on the verge of being drought stressed or were actually drought stressed (i.e., water vapor pressure deficit of $-0.029 \mathrm{MPa}$ or lower) on the day of water measurements. Whether plants in a specific plot experienced drought stress on a given date depended on the actual amount of rainfall and on the time elapsed since the last rain. However, the relative ranking of microsites with respect to soil moisture was constant through the season and consistent across years (H. Huber and M. S. Heschel, unpublished data).

The percentage of ambient light reaching the herbaceous understory after canopy closure ranged from $19 \%$ to $53 \%$, with a mode around $33 \%$ and a mean around $36 \%$ of full daylight (fig. 4A). Fifty-six percent of the plots were darker and $42 \%$ of the plots were lighter than the mean.

There was a significant correlation between seedling density and water availability $(P=.04)$, with fewer seedlings occurring in dryer microsites (table 2 ; fig. 6). There

Table 1: Distribution of performance parameters in the $50 \mathrm{mi}-$ crosites and after performing permutation tests

\begin{tabular}{|c|c|c|c|}
\hline & 50 microsites & $\begin{array}{c}\text { Random } \\
\text { distribution }\end{array}$ & $t$ value $^{\mathrm{a}}$ \\
\hline \multicolumn{4}{|c|}{ Longevity ratio: } \\
\hline Mean & -.0004 & .0003 & $.332^{\mathrm{NS}}$ \\
\hline Variance & .0011 & .0020 & $63.638^{\star * *}$ \\
\hline Skewness & -.0871 & -.6173 & $-21.650^{\star * *}$ \\
\hline Kurtosis & 1.1309 & 2.1896 & $21.611^{\star * *}$ \\
\hline \multicolumn{4}{|c|}{ Performance ratio: } \\
\hline Mean & .0368 & .0391 & $.662^{\mathrm{NS}}$ \\
\hline Variance & .0184 & .0146 & $-36.807^{\star * *}$ \\
\hline Skewness & -.2488 & .1686 & $17.042^{\star * *}$ \\
\hline Kurtosis & .8419 & .3382 & $-10.282^{\star \star *}$ \\
\hline
\end{tabular}

${ }^{a}$ These values indicate whether the distribution of longevity and performance lies outside the range predicted by a random distribution and were calculated according to Sokal and Rohlf (1995; chap. 7$)$. NS = not significant (P> .05).

*** $P<.001$. 

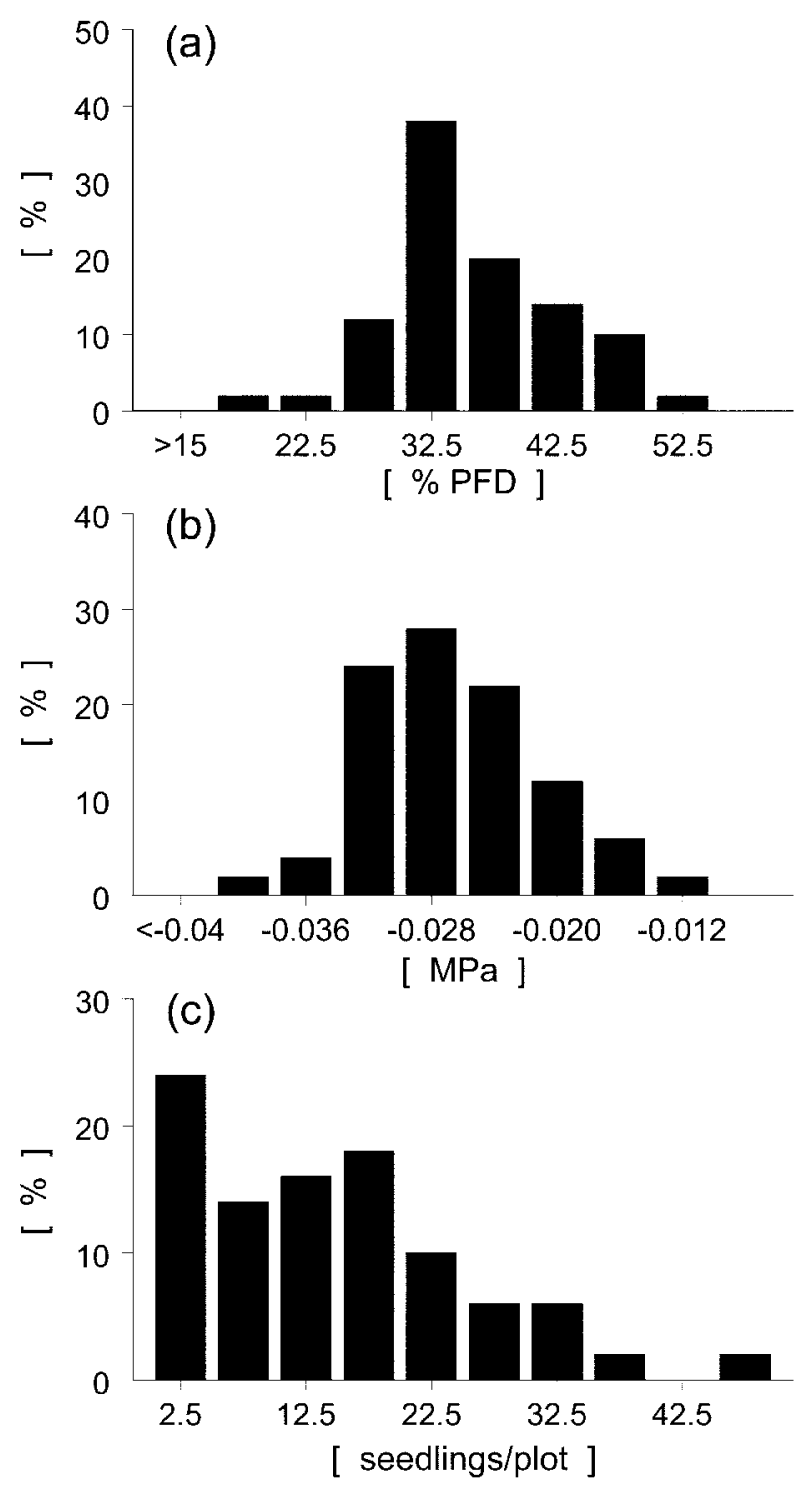

Figure 4: Frequency distribution (in percentage) of (a) light availability (measured as the percentage of direct and diffuse light penetrating the canopy), (b) water availability (measured as water vapor pressure deficit, in $\mathrm{MPa}$ ), and $(c)$ initial seedling density per $0.6 \times 0.6-\mathrm{m}$ plot of naturally occurring Impatiens capensis (counted before planting the target seedlings) among the 50 plots.

was no significant correlation between light and water or light and initial seedling density.

\section{Effects of Environmental Variation on Selection}

Longevity ratio increased significantly with microsite seedling density, soil moisture, and light availability, as predicted (table 2; fig. 5). Thus, microenvironmental variation clearly influenced the relative longevity of elongated plants, despite the homogenizing effect of synchronous mortality. Initial seedling density was not significantly correlated with the relative fecundity of elongated plants (table 2; fig. 5). However, visual inspection of the graphs revealed two unusual microsites with low fecundity ratios relative to initial seedling density. When we reanalyzed the data excluding those two microsites, there was a marginally significant positive association between initial seedling density and fecundity ratio $\left(r^{2}=0.0774 ; P=.056\right)$, although we found no a priori biological justification for excluding those particular points. The fecundity advantage to elongated plants increased significantly with increasing soil moisture, as predicted, but was not correlated with light availability (table 2; fig. 5).

The path analysis revealed both direct and indirect effects of microenvironmental conditions on the relative longevity and fecundity of elongated plants (fig. 6; table 3). A positive direct effect of seedling density on longevity ratio indicated that the relative longevity of elongated plants in a microsite increased with initial seedling density. Longevity ratio in turn had a positive effect on fecundity ratio, resulting in a positive indirect effect of seedling density on fecundity ratio. However, this positive effect was canceled out by a negative direct effect of seedling density on fecundity ratio. Consequently, the total effect of seedling density on the relative fecundity of elongated plants was small. Thus, initial seedling density in a microsite was overall a poor predictor of the selective environment for elongated plants.

Microsite soil moisture had a weak positive effect on initial seedling density (table 3; fig. 6). Soil moisture also had a direct positive effect on the relative longevity of elongated plants as well as positive direct and indirect effects on their relative fecundity. Consequently, the total effect of soil moisture on fecundity ratio was positive; selection in favor of elongated plants was stronger in wetter microsites, as predicted from functional arguments. The relative longevity of elongated plants increased with microsite light availability, resulting in a positive indirect effect of light availability on fecundity ratio. However, light availability had a strong direct negative effect on the relative fecundity of elongated plants. These opposing direct and indirect effects canceled each other out, resulting in a small total effect of light availability on the relative fitness of elongated phenotypes.

\section{Discussion}

The frequency and predictability of different selective environments are important parameters in models for the evolution of plasticity (e.g., Gomulkiewicz and Kirkpatrick 1992; de Jong 1999; Tufto 2000), but they have rarely been 
Table 2: Pearson correlations between performance parameters (longevity ratio and fecundity ratio) and environmental parameters (light, water, and density)

\begin{tabular}{|c|c|c|c|c|c|}
\hline & \multicolumn{2}{|c|}{ Performance ratio } & \multicolumn{3}{|c|}{ Environment } \\
\hline & Longevity & Fecundity & Light & Water & Density \\
\hline \multicolumn{6}{|c|}{ Performance ratio: } \\
\hline Longevity & & & & & \\
\hline Fecundity & $.410^{\star *}$ & & & & \\
\hline \multicolumn{6}{|c|}{ Environment: } \\
\hline Light & $.365^{\star *}$ & -.182 & & & \\
\hline Water & $.340^{*}$ & $.331^{\star}$ & .043 & & \\
\hline Density & $.389^{\star *}$ & .075 & .094 & $.286^{*}$ & \\
\hline
\end{tabular}

measured empirically in natural populations. This study provides experimental evidence for heterogeneous and unpredictable selection on density-induced shade-avoidance phenotypes within a natural population of Impatiens capensis. Local seedling density, the inductive environmental cue, was a surprisingly poor predictor of selection on shade-avoidance traits in this study population. At least some of this unpredictability may result from microenvironmental variation in resource availability. In particular, the shade-avoidance phenotype was more costly in dry microsites. Thus, environmental heterogeneity in resource availability can affect the relative costs and benefits of expressing shade-avoidance traits independent of local seedling density, the inductive environmental cue, and may thus reduce the reliability of that cue. Such microenvironmental variation may be an important determinant of the dramatic variation we observed among microsites in the strength and direction of selection on shade-avoidance phenotypes. These results have interesting implications for the evolution and maintenance of plastic shade-avoidance traits within this natural population.

The reliability of the inductive environmental cue for predicting selection on induced phenotypes may strongly influence how reaction norms will evolve (de Jong 1999; Tufto 2000; Sultan and Spencer 2002). In our study, path analysis revealed a negligible total effect of initial seedling density on the relative fitness of elongated plants. Although the relative longevity of elongated plants increased with microsite seedling density, as predicted by the shadeavoidance hypothesis, this effect was canceled out by an unpredicted direct negative effect of initial density on fecundity ratio. This result is rather surprising because two prior density manipulation experiments in this site have revealed density-dependent selection on elongation traits (Dudley and Schmitt 1996; Donohue et al. 2000a). We may have lacked power to detect such an association in this study given the unusually small range of natural den- sities in our study population in the year of our experiment. In addition, microenvironmental variation independent of conspecific density was also a far more important factor in this study, in which experimental plants were planted into extant vegetation in 50 microsites spanning a wide range of environmental conditions, than in the manipulative experiments, which were confined to a much smaller area where existing vegetation was removed. Under these circumstances, initial Impatiens seedling density was an inaccurate predictor of the selective environment experienced within microsites by our experimental plants, suggesting that models of reaction norm evolution when environmental cues are unreliable (de Jong 1999; Tufto 2000) may be relevant for understanding the evolution of shade-avoidance responses in our study population.

We observed significant and substantial microenvironmental variation in selection on plastic shade-avoidance traits. In some microsites, the elongated phenotype was highly advantageous, and in other microsites it was strongly selected against. However, the distribution of relative fecundity of elongated plants was roughly bell shaped (although slightly skewed), and consequently the two phenotypes had similar fecundity in a high proportion of the microsites. Probably within these intermediate microsites stabilizing selection favored an intermediate degree of elongation, although our experiment, designed to maximize the number of microsites sampled, lacked power to detect such stabilizing selection. Note that, although our manipulation created two extreme phenotypes, phytochrome-mediated stem elongation is actually a continuous function of R : FR and density (Smith 1982; Ballaré et al. 1990), and therefore intermediate phenotypes should be common under natural conditions.

The graded nature of the shade-avoidance response, together with the observation of a relatively continuous distribution of selective environments in our experiment, 
longevity ratio

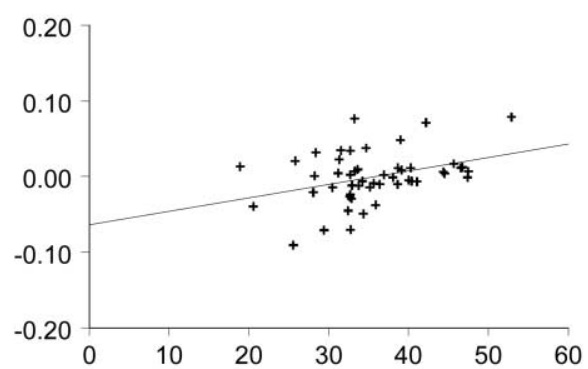

fecundity ratio
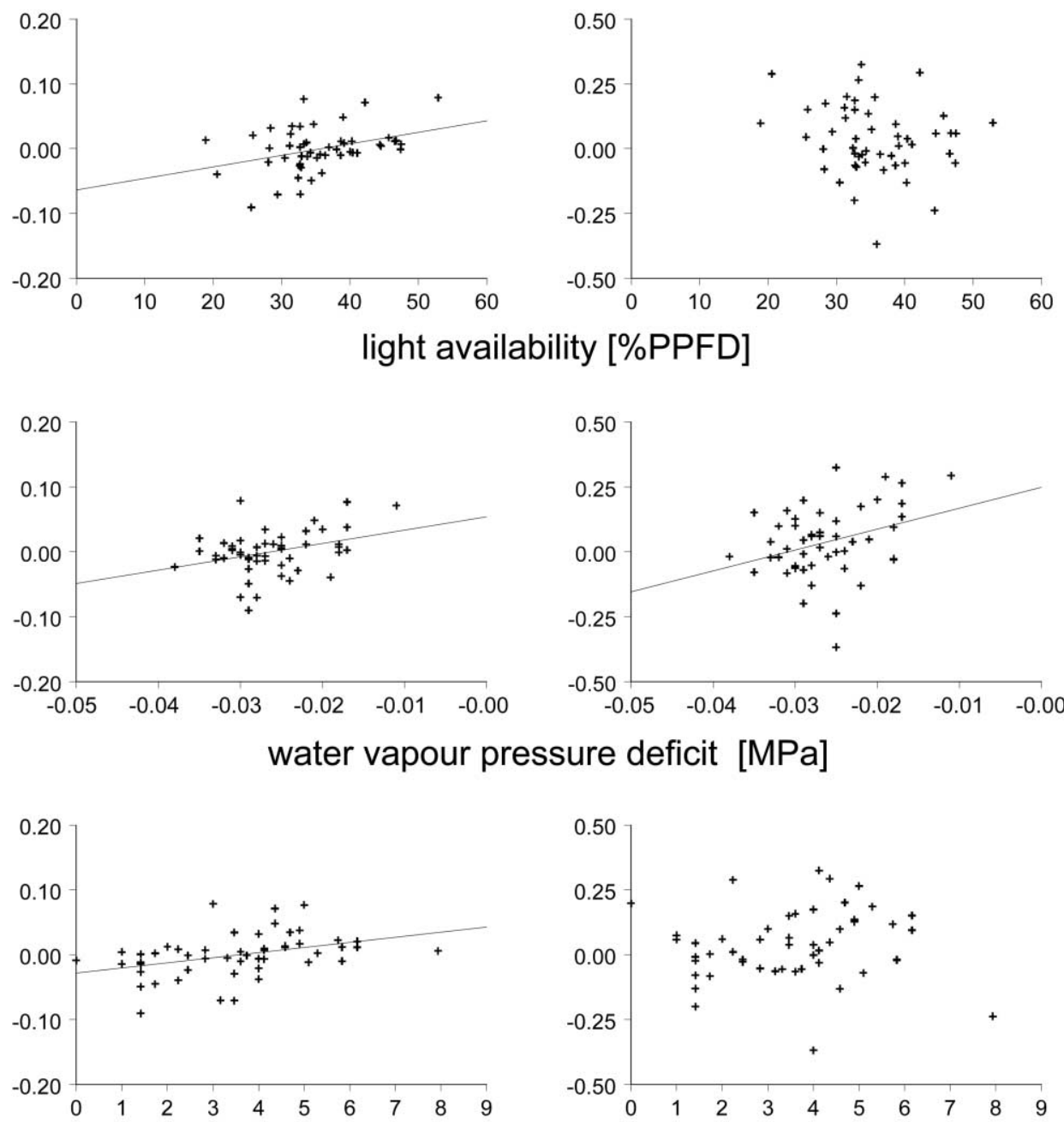

sqrt (initial seedling number) per plot

Figure 5: Effects of light availability (first row), water vapor pressure deficit (second row), and the square root-transformed initial density of Impatiens capensis seedlings (last row) on longevity ratio (left column) and fecundity ratio (right column). For calculation of fecundity ratio and longevity ratio, see text. Note that longevity and fecundity ratio are depicted on different scales. The standardized regression coefficient obtained in a multiple regression of light availability, water availability, and seedling density on the two performance parameters were longevity ratio $=0.299^{*} \times 1$ light availability $+0.252^{*} \times$ water availability $+0.338^{* *} \times$ seedling density, and fecundity ratio $=-0.004 \times$ light availability $+0.340^{* *} \times$ water availability $-0.196 \times$ seedling density. Asterisks after regression coefficients indicate statistical significance.

suggests that the evolution of shade-avoidance responses in natural plant populations is best described by models that treat reaction norms as functions of an ordered environmental variable (e.g., Gomulkiewicz and Kirkpatrick 1992; de Jong 1999; Kingsolver et al. 2001). In such models, the strength of selection in an environment is weighted by the frequency of that environment, and consequently the frequency distribution of selective environments has an important influence on the shape of the evolved reaction norm (de Jong 1999; Kingsolver et al. 2001). For example, when the selective environment is unpredictable from the inductive cue, a slight asymmetry in the frequency distribution of selective environments can cause selection to "pull harder" on one side of the environmental distribution and can lead to the evolution of a curved reaction norm if genetic variation exists for curvature, even 


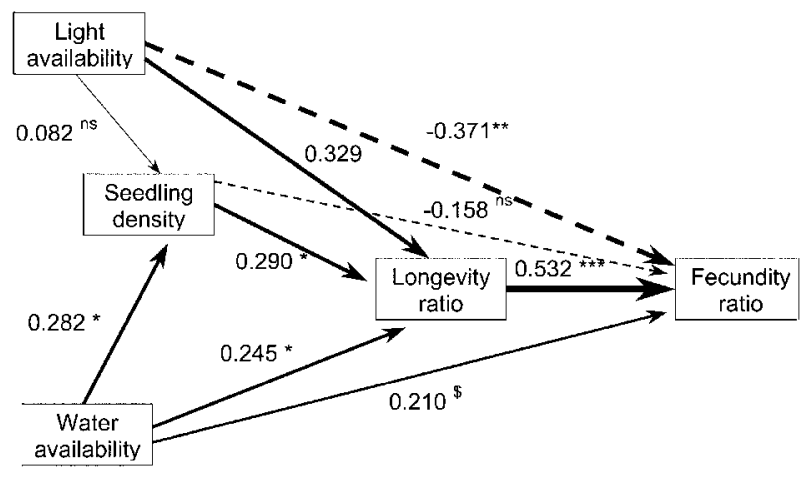

Figure 6: Path diagram showing the effects of abiotic resource availability on biotic resource availability mediated by initial seedling density, as well as the effects of resource availability on longevity ratio and fecundity ratio. Dashed lines indicate negative coefficients; the width of the arrow indicates the strength of the effect: dollar sign, $P<.1$; one asterisk, $P<$ .05 ; two asterisks, $P<.01$; and three asterisks, $P<.001$. Variation due to error is not included for simplicity.

if the optimal reaction norm is linear (de Jong 1999). The skewed distribution and unpredictability of selective environments observed in this study suggest that this prediction may be relevant for I. capensis. Consistent with the prediction, reaction norms of stem elongation to continuous density variation are curvilinear, and the shape of those reaction norms is genetically variable (J. Stinchcombe, M. S. Heschel, and J. Schmitt, unpublished data). Thus, the observed asymmetry in the distribution of selective environments may be evolutionarily important.

Much of the observed variation in selection on shadeavoidance traits may have resulted from microenvironmental variation in resource availability and consequently in the cost of expressing the shade-avoidance phenotype. In particular, the relative fecundity of elongated plants declined significantly with soil moisture, as predicted from functional arguments. Remarkably, we also observed a strong positive effect of soil moisture on the relative longevity of elongated plants despite the homogenizing effects of a major episode of mortality, suggesting that elongated plants may have died prematurely in dry microsites but may have been more likely to survive the mass mortality episode in wet microsites. These observations are strong evidence that drought stress may select against shadeavoidance traits such as stem elongation by increasing their cost of expression. A major cost of phytochrome-induced investment into elongated stems is reduced allocation to roots, which could exacerbate water stress (Maliakal et al. 1999). Impatiens capensis is characterized by a shallow root system (Waller 1984; Heschel and Hausmann 2001) and is therefore likely to experience the negative effects of even moderate droughts as the uppermost soil layers dry out more quickly than deeper soil layers. In addition, elongated plants whose leaves are higher up in the canopy may experience higher evaporation loads than plants with leaves in lower regions of the canopy where the air humidity is higher, there is less wind, and direct radiation is lower. This combination of factors may explain the observed strong selection against expression of the elongated phenotype in dry microsites. The low correlation between seedling density and soil moisture within microsites indicates that initial density was a poor predictor of the availability of resources that could affect the cost of expression of the elongated phenotype, and therefore the strength and direction of selection on elongation traits.

The strength of this selective pressure, and thus the frequency of microsites in which the fitness benefits of the shade-avoidance phenotype outweigh the cost of water stress, may change with temporal variation in rainfall. Although the relative ranking of microsites with respect to soil moisture is consistent within years as well as from year to year (M. S. Heschel, unpublished data), the absolute positioning of microsites along a dry to wet axis may shift in relatively wet or dry years. As a result, a given microsite may be sufficiently wet at one time, but too dry at another time, to favor induction of shade-avoidance traits. Seedling density also varies substantially from year to year (M. S. Heschel, unpublished data). Correspondingly, the frequency of microsites favoring the alternative phenotypes may differ between years. In our experimental population, the majority of the sites become too dry to promote further growth and survival of Impatiens at some point during the growing season (M. S. Heschel, unpublished data). The timing and the intensity of the drought may determine selection for or against a certain phenotype. Drought episodes early in the season may confer especially strong selection intensities against elongation in drier microsites (M. S. Heschel, unpublished data). Thus, temporal variation in resource availability may result in variation in the cost of expressing shade-avoidance traits, leading to temporal variation in selection on reaction norms of those traits to density.

Microenvironmental variation in light resource availability, which was not significantly correlated with either density or soil moisture, was also predicted, based on functional arguments, to increase the relative fitness of the shade-avoidance phenotype. As predicted, high levels of overhead light enhanced the relative longevity of elongated plants. One possible explanation for this result is that the advantage of overtopping neighbors may be higher in light gaps. Elongated plants in bright microsites may better buffer additional maintenance costs of longer stems than elongated plants experiencing carbohydrate limitation due to deep primary canopy shade. If so, the cost of elongation could vary with the light environment. However, an un- 
Table 3: Total, direct, and indirect path coefficients of the effects of water availability, light availability, initial seedling density, and longevity ratio on seedling density, longevity ratio, and fecundity ratio calculated by using a path analysis (see fig. 6)

\begin{tabular}{|c|c|c|c|c|c|c|c|c|c|}
\hline & \multicolumn{3}{|c|}{ Total effects } & \multicolumn{3}{|c|}{ Direct effects } & \multicolumn{3}{|c|}{ Indirect effects } \\
\hline & $\begin{array}{c}\text { Seedling } \\
\text { density }\end{array}$ & $\begin{array}{l}\text { Longevity } \\
\text { ratio }\end{array}$ & $\begin{array}{l}\text { Fecundity } \\
\text { ratio }\end{array}$ & $\begin{array}{c}\text { Seedling } \\
\text { density }\end{array}$ & $\begin{array}{l}\text { Longevity } \\
\text { ratio }\end{array}$ & $\begin{array}{l}\text { Fecundity } \\
\text { ratio }\end{array}$ & $\begin{array}{l}\text { Seedling } \\
\text { density }\end{array}$ & $\begin{array}{l}\text { Longevity } \\
\text { ratio }\end{array}$ & $\begin{array}{l}\text { Fecundity } \\
\text { ratio }\end{array}$ \\
\hline Water & .282 & .327 & .339 & .282 & .245 & .210 & $\ldots$ & .082 & .129 \\
\hline Light & .082 & .353 & -.196 & .082 & .329 & -.371 & $\ldots$ & .024 & .174 \\
\hline Density & $\ldots$ & .290 & -.006 & $\ldots$ & .290 & -.158 & $\ldots$ & $\ldots$ & .154 \\
\hline Longevity & $\ldots$ & $\ldots$ & .532 & $\ldots$ & $\ldots$ & .532 & $\ldots$ & $\ldots$ & $\ldots$ \\
\hline
\end{tabular}

predicted negative direct effect of light availability on fecundity ratio indicated that elongated plants had lower relative fecundity in brighter microsites, canceling out the indirect positive effect mediated through longevity. The mechanism driving this direct negative effect is unclear. One possibility is that elongated plants were disproportionately lacking in some resource necessary for translating high light availability into fruit production. For example, the lower root-shoot ratio and maximal photosynthetic assimilation rate observed in elongated plants by Maliakal et al. (1999) could have resulted in lower availability of carbon or mineral nutrients for reproduction. Whatever the underlying mechanisms, it appears that light resource availability had little overall impact on the cost of expressing shade-avoidance traits.

Although our experiment was not designed to estimate genetic variation, the observation of significant differences among lines in elongation response to the $\mathrm{R}$ : FR pretreatment is consistent with earlier quantitative genetic studies that have detected genetic variation in shade-avoidance responses in natural populations of $I$. capensis (Donohue and Schmitt 1999; Donohue et al. 2000b) and other species (Skávlóvá and Krahulec 1992; van Hinsberg 1997). What maintains this variation in our study population, given the evidence that selection acts to reduce plasticity to density in this woodland site (Donohue et al. 2000a)? Interestingly, plasticity to density and genetic variation in density responses are not detectable under the natural conditions of our woodland study population, although lines differ significantly in trait means (Donohue et al. 2000b), but substantial plasticity to density and genetic variation in that plasticity are revealed under greenhouse conditions or when lines from our study population are exposed to the broader range of natural densities in a nearby open site (Donohue et al. 2000b). Perhaps the range of densities experienced in the woodland site is insufficient to elicit strong shade-avoidance responses against the background $\mathrm{R}$ : FR signal from the forest canopy (Morgan and Smith 1979), and selection has not acted strongly to reduce variation in plastic response to environments rarely encountered in this population (e.g., Arnold and Peterson 2002), since the capacity for plasticity is not intrinsically costly in this system (Donohue et al. 2000a). However, substantial genetic variation in plasticity to density also exists in lines originating in the nearby open site, where selection favors plasticity to density (Donohue et al. 2000a). Why has this selection not resulted in fixation of a single, optimal reaction norm, as classic quantitative genetic models predict (e.g., Via and Lande 1985; Gomulkiewicz and Kirkpatrick 1992)?

The resolution to these questions may lie in recent theoretical models that predict that unpredictable selection in structured populations will result in local genetic differentiation of reaction norms (de Jong 1999; Tufto 2000). Our results suggest that, at least in our study population, the cues eliciting the shade-avoidance response are imperfect predictors of selection on the resulting phenotype, probably largely due to unpredictable microenvironmental variation in water availability, which modulates the cost of expressing shade-avoidance traits. Moreover, there is good evidence for microgeographic genetic structure both within and between Impatiens populations (Schemske 1984; Knight and Waller 1987; Schoen and Latta 1989; Argyres and Schmitt 1991), probably due to habitual inbreeding and limited seed dispersal (Schmitt et al. 1985) resulting in restricted gene flow. There is also strong evidence for spatially heterogeneous selection on shadeavoidance traits, as observed here within our study population as well as previously between closely adjacent populations in different habitats (Donohue et al. 2000a). Moreover, temporal variation in resource availability may lead to variation in expression of these costs and thus to temporal variation in selection. Thus, the natural history of Impatiens is entirely consistent with the conditions expected to maintain microgeographic genetic variation in plasticity and prevent fixation of a single optimal reaction norm.

Similar conditions may frequently occur in natural plant populations, which often experience restricted gene flow (Knight and Waller 1987; Dube 1988; Hamrick and Godt 1989), microenvironmental variation (Stewart and Schoen 1987; Bell et al. 1991; Lechowicz and Bell 1991), and het- 
erogeneous natural selection on the scale of a few centimeters to a few meters (Kalisz 1986; Stewart and Schoen 1987; Bell et al. 1991; Lechowicz and Bell 1991; Stratton 1994, 1995; Stratton and Bennington 1996). However, the predictability, pattern, and frequency of selection on plastic traits have rarely been assessed (Weis and Gorman 1990; Kingsolver et al. 2001), in part because plastic responses to environmental variation prevent expression of a broad range of phenotypes across all environments. In this study, we adopted an experimental phytometer approach, experimentally inducing extreme alternative phenotypes and exposing them to microenvironmental variation in a natural population. This enabled us to measure the frequency and predictability of selection on shade-avoidance traits. By simultaneously measuring environmental variables within the same set of microsites and on the same genetic background, we could evaluate the reliability of seedling density, the inductive cue, for predicting selection on shade avoidance, as well as the potential impact of water and light resource availability on the relative fitness of elongated plants. We detected substantial and unpredictable variation in the strength and direction of selection on a fine spatial scale within a natural population. An important determinant of this variation was unpredictable variation in soil moisture, resulting in variable costs of expressing shade-avoidance traits. Thus, unpredictable environmental variation in resource availability may alter the relative costs and benefits of expressing an induced phenotype, with important consequences for the evolutionary dynamics of adaptive plasticity.

\section{Acknowledgments}

We thank F. Jackson for excellent care for the plants in the greenhouse. We also thank L. Dorn, Z. German, A. Giunta, M. Gotcsik, K. Graveur, C. Riginos, J. Stuefer, Y. Toyonaga, and C. Weinig for help with the experiment and H. de Kroon, S. Kalisz, J. Stinchcombe, J. Stuefer, A. Weis, and an anonymous reviewer for insightful comments on a previous version of the manuscript. We are grateful to R. Oi at Mitsui Chemicals for providing the R: FR treatment panels. This research was supported by National Science Foundation grants DEB-9806858 and DEB0129018 to J.S.

\section{Literature Cited}

Aphalo, P. J., and C. L. Ballaré. 1995. On the importance of information-acquiring systems in plant-plant interactions. Functional Ecology 9:5-14.

Arbuckle, J. L., and W. Wothke. 1999. Amos 4.0 user's guide. SPSS, SmallWaters, Chicago.

Argyres, A. Z., and J. Schmitt. 1991. Microgeographic genetic structure of morphological and life-history traits in a natural population of Impatiens capensis. Evolution 45:178-189.

Arnold, S. J., and C. R. Peterson. 2002. A model for optimal reaction norms: the case of the pregnant garter snake and her temperature-sensitive embryos. American Naturalist 160:306-316.

Ballaré, C. L., R. A. Sánchez, A. L. Scopel, J. J. Casal, and C. M. Ghersa. 1987. Early detection of neighbour plants by phytochrome perception of spectral changes in reflected sunlight. Plant Cell and Environment 10:551557.

Ballaré, C. L., A. L. Scopel, and R. A. Sánchez. 1990. Farred radiation reflected from adjacent leaves: an early signal of competition in plant canopies. Science 24:329332.

- 1991. On the opportunity cost of the photosynthate invested in stem elongation reactions mediated by phytochrome. Oecologia (Berlin) 86:561-567.

Bell, G., M. J. Lechowicz, and D. J. Schoen. 1991. The ecology and genetics of fitness in forest plants. III. Environmental variance in natural populations of Impatiens pallida. Journal of Ecology 79:697-713.

Bradshaw, A. D. 1965. Evolutionary significance of phenotypic plasticity in plants. Advances in Genetics 13: 115-155.

Casal, J. J., and H. Smith. 1989. The function, action and adaptive significance of phytochrome in light-grown plants. Plant Cell and Environment 12:855-862.

Casal, J. J., C. L. Ballaré, M. Tourn, and R. A. Sánchez. 1994. Anatomy, growth and survival of a long-hypocotyl mutant of Cucumis sativus deficient in phytochrome B. Annals of Botany 73:569-575.

Cipollini, D. E., and J. C. Schultz. 1999. Exploring cost constraints on stem elongation in plants using phenotypic manipulation. American Naturalist 153:236-242.

de Jong, G. 1995. Phenotypic plasticity as a product of selection in a variable environment. American Naturalist 145:493-512.

1999. Unpredictable selection in a structured population leads to local genetic differentiation in evolved reaction norms. Journal of Evolutionary Biology 12: 839-851.

DeWitt, T. J. 1998. Costs and limits of phenotypic plasticity: tests with predator-induced morphology and life history in a freshwater snail. Journal of Evolutionary Biology 11:465-480.

DeWitt, T. J., A. Sih, and D. S. Wilson. 1998. Cost and limits of phenotypic plasticity. Trends in Ecology \& Evolution 13:77-81.

Donohue, K., and J. Schmitt. 1999. The genetic architecture of plasticity to density in Impatiens capensis. Evolution 53:1377-1386.

Donohue, K., E. Hammond Pyle, D. Messiqua, M. S. Hes- 
chel, and J. Schmitt. 2000a. Density dependence and population differentiation of genetic architecture in Impatiens capensis in natural environments. Evolution 54: 1969-1981.

Donohue, K., D. Messiqua, E. Hammond Pyle, M. S. Heschel, and J. Schmitt. 2000b. Evidence of adaptive divergence in plasticity: density- and site-dependent selection on shade-avoidance responses in Impatiens capensis. Evolution 54:1956-1968.

Donohue, K., E. Hammond Pyle, D. Messiqua, M. S. Heschel, and J. Schmitt. 2001. Adaptive divergence in plasticity in natural populations of Impatiens capensis and its consequences for performance in novel habitats. Evolution 55:692-702.

Dorn, L. A., E. Hammond Pyle, and J. Schmitt. 2000. Plasticity to cues and resources in Arabidopsis thaliana: testing for adaptive value and costs. Evolution 54:19821994.

Dube, D. 1988. Flight path of pollinators foraging on Impatiens: decision rules and their implications for gene flow. MsC thesis. McGill University, Montreal, Quebec.

Dudley, S. A., and J. Schmitt. 1995. Genetic differentiation in morphological responses to simulated foliage shade between populations of Impatiens capensis from open and woodland sites. Functional Ecology 9:655-666.

- 1996. Testing the adaptive plasticity hypothesis: density-dependent selection on manipulated stem length in Impatiens capensis. American Naturalist 147: $445-465$.

Fry, J. D., S. L. Heinsohn, and T. F. C. Mackay. 1996. The contribution of new mutations to genotype-environment interaction for fitness in Drosophila melanogaster. Evolution 50:2316-2327.

Gilbert, I. R., P. G. Jarvis, and H. Smith. 2001. Proximity signal and shade avoidance differences between early and late successional trees. Nature 411:792-795.

Gleason, H. A., and A. Cronquist. 1963. Manual of vascular plants of northeastern United States and adjacent Canada. Wadsworth, Boston.

Gomulkiewicz, R., and M. Kirkpatrick. 1992. Quantitative genetics and the evolution of reaction norms. Evolution 46:390-411.

Hamrick, J. L., and M. J. W. Godt. 1989. Allozyme diversity in plant species. Pages 43-63 in A. H. D. Brown, M. T. Clegg, A. L. Kahler, and B. S. Weir, eds. Plant population genetics, breeding, and genetic resources. Sinauer, Sunderland, Mass.

Heschel, M. S., and N. J. Hausmann. 2001. Population differentiation for abscisic acid responsiveness in Impatiens capensis (Balsaminaceae). International Journal of Plant Sciences 162:1253-1260.

Huber, H., and L. Wiggerman. 1997. Shade avoidance in the clonal herb Trifolium fragiferum: a field study with experimentally manipulated vegetation height. Plant Ecology 130:53-62.

Huber, H., A. Fijan, and H. J. During. 1998. A comparative study of spacer plasticity in erect and stoloniferous herbs. Oikos 81:576-586.

Kalisz, S. 1986. Variable selection on the timing of germination in Collinsia verna (Scrophulariaceae). Evolution 40:479-491.

Kawecki, T. J., and S. C. Stearns. 1993. The evolution of life histories in spatially heterogeneous environments: optimal reaction norms revisited. Evolutionary Biology 7:155-174.

Kingsolver, J. G. 1995a. Fitness consequences of seasonal polyphenism in western white butterflies. Evolution 49: 942-954.

- 1995b. Viability selection on seasonally polyphenic traits: wing dimorphism in western white butterflies. Evolution 49:932-941.

- 1996. Experimental manipulation of wing pigment pattern and survival in western white butterflies. American Naturalist 147:296-306.

Kingsolver, J. G., R. Gomulkiewicz, and P. A. Carter. 2001. Variation, selection and evolution of function-valued traits. Genetica 112/113:87-104.

Kliebenstein, D. J., A. Figuth, and T. Mitchell-Olds. 2002. Genetic architecture of plastic methyl jasmonate responses in Arabidopsis thaliana. Genetics 161:16851696.

Knight, S. E., and D. M. Waller. 1987. Genetic consequences of outcrossing in the cleistogamous annual, Impatiens capensis. I. Population-genetic structure. Evolution 41:969-978.

Lechowicz, M. J., and G. Bell. 1991. The ecology and genetics of fitness in forest plants. II. Microspatial heterogeneity of the edaphic environment. Journal of Ecology 79:687-696.

Leck, M. A. 1979. Germination behaviour of Impatiens capensis Meerb. Bartonia 46:1-14.

- 1996. Germination of macrophytes from a Delaware River tidal freshwater wetland. Bulletin of the Torrey Botanical Club 123:48-67.

Maliakal, S. K., K. McDonnell, S. A. Dudley, and J. Schmitt. 1999. Effects of red to far-red ratio and plant density on biomass allocation and gas exchange in Impatiens capensis. International Journal of Plant Sciences 160: 723-733.

Morgan, D. C., and H. Smith. 1979. A systematic relationship between phytochrome-controlled development and species habitat, for plants grown in simulated natural radiation. Planta 145:253-258.

Niklas, K. J. 1995. Plant height and the properties of some herbaceous stems. Annals of Botany 75:133-142.

Novoplansky, A., D. Cohen, and T. Sachs. 1990. How Por- 
tulaca seedlings avoid their neighbours. Oecologia (Berlin) 82:490-493.

Olsson, M., and T. Uller. 2002. Developmental stability and genetic architecture: a comparison within and across thermal regimes in tadpoles. Journal of Evolutionary Biology 15:625-633.

Pigliucci, M., J. Whitton, and C. D. Schlichting. 1995. Reaction norms of Arabidopsis. I. Plasticity of characters and correlations across water, nutrient and light gradients. Journal of Evolutionary Biology 8:421-438.

Scheiner, S. M. 1993. Genetics and evolution of phenotypic plasticity. Annual Review of Ecology and Systematics 24:35-68.

- 1998. The genetics of phenotypic plasticity. VII. Evolution in a spatially structured environment. Journal of Evolutionary Biology 11:303-320.

Scheiner, S. M., and D. Berrigan. 1998. The genetics of phenotypic plasticity. VIII. The cost of plasticity in Daphnia pulex. Evolution 52:368-378.

Schemske, D. W. 1984. Population structure and local selection in Impatiens pallida (Balsaminaceae), a selfing annual. Evolution 38:817-832.

Schlichting, C. D. 1989. Phenotypic plasticity in Phlox. II. Plasticity of character correlations. Oecologia (Berlin) 78:496-501.

Schmitt, J. 1993. Reaction norms of morphological and life-history traits to light availability in Impatiens capensis. Evolution 47:1654-1668.

Schmitt, J., and D. W. Ehrhardt. 1990. Enhancement of inbreeding depression by dominance and suppression in Impatiens capensis. Evolution 44:269-278.

Schmitt, J., and R. D. Wulff. 1993. Light spectral quality, phytochrome and plant competition. Trends in Ecology \& Evolution 8:47-51.

Schmitt, J., D. W. Erhardt, and D. Swartz. 1985. Differential dispersal of self-fertilized and outcrossed progeny in jewelweed (Impatiens capensis). American Naturalist 126:570-575.

Schmitt, J., J. Eccleston, and D. W. Ehrhardt. 1987. Dominance and suppression, size-dependent growth, and self-thinning in a natural Impatiens capensis population. Journal of Ecology 75:651-665.

Schmitt, J., A. C. McCormac, and H. Smith. 1995. A test of the adaptive plasticity hypothesis using transgenic and mutant plants disabled in phytochrome-mediated elongation responses to neighbors. American Naturalist 146:937-953.

Schmitt, J., S. A. Dudley, and M. Pigliucci. 1999. Manipulative approaches to testing adaptive plasticity: phytochrome-mediated shade-avoidance response in plants. American Naturalist 154(suppl.):S43-S54.

Schmitt, J., J. R. Stinchcombe, M. S. Heschel, and H. Huber. 2003. The adaptive evolution of plasticity: phytochrome-mediated shade avoidance responses. Integrative and Comparative Biology 43:459-469.

Schmitt, J. A., and S. E. Gamble. 1990. The effect of distance from the parental site on offspring performance and inbreeding depression in Impatiens capensis: test of the local adaptation hypothesis. Evolution 44:20222030.

Schoen, D. J., and R. G. Latta. 1989. Spatial autocorrelation of genotypes in populations of Impatiens pallida and Impatiens capensis. Heredity 63:181-189.

Skálová, H., and F. Krahulec. 1992. The response of three Festuca rubra clones to changes in light quality and plant density. Functional Ecology 6:282-290.

Smith, H. 1982. Light quality, photoreception, and plant strategy. Annual Review of Plant Physiology 33:481-518. 1995. Physiological and ecological function within the phytochrome family. Annual Review of Plant Physiology and Plant Molecular Biology 46:289-315.

Smith, H., and G. C. Whitelam. 1997. The shade-avoidance syndrome: multiple responses mediated by multiple phytochromes. Plant Cell and Environment 20:840-844.

Smith, H., J. J. Casal, and G. M. Jackson. 1990. Reflection signals and the perception by phytochrome of the proximity of neighboring vegetation. Plant Cell and Environment 13:73-38.

Sokal, R. R., and F. J. Rohlf. 1995. Biometry. 3d ed. W. H. Freeman, New York.

Stewart, S. C., and D. J. Schoen. 1987. Pattern of phenotypic viability and fecundity selection in a natural population of Impatiens pallida. Evolution 41:12901301.

Stratton, D. A. 1994. Genotype-by-environment interactions for fitness of Erigeron annuus show fine-scale selective heterogeneity. Evolution 48:1607-1618.

- 1995. Spatial scale of variation in fitness of Erigeron annuus. American Naturalist 146:608-624.

Stratton, D. A., and C. C. Bennington. 1996. Measuring spatial variation in natural selection using randomlysown seeds of Arabidopsis thaliana. Journal of Evolutionary Biology 9:215-228.

Sultan, S. E. 1995. Phenotypic plasticity and plant adaptation. Acta Botanica Neerlandica 44:363-383.

Sultan, S. E., and H. G. Spencer. 2002. Metapopulation structure favors plasticity over local adaptation. American Naturalist 160:271-283.

ter Steege, H. 1996. Winphot 5: a programme to analyze vegetation indices, light and light quality from hemispherical photographs. Tropenbos Guyana Programme, Georgetown, Guyana.

Tufto, J. 2000. The evolution of plasticity and nonplastic spatial and temporal adaptations in the presence of imperfect environmental cues. American Naturalist 156: 121-130. 
van Hinsberg, A. 1997. Morphological variation in Plantago lanceolata L.: effects of light quality and growth regulators on sun and shade populations. Journal of Evolutionary Biology 10:687-701.

van Tienderen, P. H. 1991. Evolution of generalists and specialists in spatially heterogeneous environments. Evolution 45:1317-1331.

Via, S., and R. Lande. 1985. Genotype-environment interaction and the evolution of phenotypic plasticity. Evolution 39:505-522.

Waller, D. M. 1979. The relative cost of self- and crossfertilized seeds in Impatiens capensis (Balsaminaceae). American Journal of Botany 66:213-320.
1984. Differences in fitness between seedlings derived from cleistogamous and chasmogamous flowers in Impatiens capensis. Evolution 38:427-440.

Weinig, C. 2000. Differing selection in alternative competitive environments: shade-avoidance responses and germination timing. Evolution 54:124-136.

Weis, A. E., and W. L. Gorman. 1990. Measuring selection on reaction norms: an exploration of the EurostaSolidago system. Evolution 44:820-831. 